\title{
Erratum: OTUB1 de-ubiquitinating enzyme promotes prostate cancer cell invasion in vitro and tumorigenesis in vivo
}

Diego Iglesias-Gato ${ }^{1 *}$, Yin-Choy Chuan ${ }^{1}$, Ning Jiang ${ }^{1,2}$, Charlotte Svensson ${ }^{1}$, Jing Bao ${ }^{1,2}$, Zhiqun Shang ${ }^{2}$, Indranil Paul', Lars Egevad ${ }^{3}$, Benedikt M Kessler ${ }^{4}$, Pernilla Wikström ${ }^{5}$, Yuanjie Niu ${ }^{2}$ and Amilcar Flores-Morales ${ }^{{ }^{*}}$

\section{Erratum}

After publication of this study [1], we found that we unintentionally failed to provide the complete list of all coauthors. This error has now been corrected and the full list of authors contributing to this work is included. Authors' contributions and Competing interests sections have been modified accordingly.

\section{Competing interests}

The authors declare that they have no competing interests.

\section{Authors' contributions}

DI-G carried out experimental work, analyzed the data and wrote the manuscript. Y-CC conducted experimental work and analyzed the data NJ, CS, JB, ZS, and IP performed experiments. LE provided the TMA. PW performed immunohistochemical work and analyzed the results. BMK discussed the results, provided reagents and help to draft the manuscript. NY supervised animal experiments. AF-M designed, supervised and coordinated the study and wrote the manuscript. All authors read and approved the final manuscript.

\section{Author details \\ 'The Novo Nordisk Foundation Center for Protein Research, Faculty of Health Sciences, University of Copenhagen, 2200 Copenhagen, Denmark. ${ }^{2}$ Tianjin Institute of Urology, Tianjin Medical University, 300211 Tianjin, China. ${ }^{3}$ Department of Surgical Science Karolinska Institutet, Section of Urology, 17176 Stockholm, Sweden. ${ }^{4}$ Nuffield Department of Clinical Medicine, Target Discovery Institute, University of Oxford, OX37BN Oxford, UK. ${ }^{5}$ Department of Pathology, Umeå University, 90185 Umeå, Sweden.}

Received: 4 March 2015 Accepted: 4 March 2015 Published online: 18 April 2015

\section{Reference}

1. Iglesias-Gato D, Chuan YC, Jiang N, Svensson C, Bao J, Paul I, et al. OTUB1 de-ubiquitinating enzyme promotes prostate cancer cell invasion in vitro and tumorigenesis in vivo. Mol Cancer. 2015;14:8.

\footnotetext{
*Correspondence: diego.iglesias@cpr.ku.dk; amilcar.flores@cpr.ku.dk

${ }^{1}$ The Novo Nordisk Foundation Center for Protein Research, Faculty of Health Sciences, University of Copenhagen, 2200 Copenhagen, Denmark
} Full list of author information is available at the end of the article
Submit your next manuscript to BioMed Central and take full advantage of:

- Convenient online submission

- Thorough peer review

- No space constraints or color figure charges

- Immediate publication on acceptance

- Inclusion in PubMed, CAS, Scopus and Google Scholar

- Research which is freely available for redistribution 